\title{
AUSGeoid09: a more direct and more accurate model for converting ellipsoidal heights to AHD heights
}

\author{
N.J. Brown, G. Hu, G.M. Johnston \\ National Geospatial and Reference Systems Project, Geospatial and Earth Monitoring \\ Division, Geoscience Australia, GPO Box 378, Canberra, ACT 2601, Australia \\ Fax: +61 26249 9929; Emails: Nicholas.Brown@ga.gov.au; Guorong.Hu@ga.gov.au; \\ Gary.Johnston@ga.gov.au
}

\author{
W.E. Featherstone \\ Western Australian Centre for Geodesy \& The Institute for Geoscience Research, \\ Curtin University of Technology, GPO Box U1987, Perth, WA 6845, Australia \\ Fax: +61 89266 2703; Emails: W.Featherstone@curtin.edu.au
}

\begin{abstract}
In an absolute sense, AUSGeoid09 is an order of magnitude more accurate than AUSGeoid98 at converting ellipsoidal heights to Australian Height Datum (AHD) heights and vice versa. Results of this study show AUSGeoid09 can be used to compute AHD heights from Global Navigation Satellite System (GNSS) ellipsoidal heights with an uncertainty of less than \pm 0.03 $\mathrm{m}$ (one sigma). The improvement is largely due to the inclusion of a geometric component in AUSGeoid09 that accounts for the spatially varying offset between a gravimetric quasigeoid model and the AHD. This geometric component was calculated using least squares collocation in cross validation mode and then added to the gravimetric quasigeoid. Although previous AUSGeoid models were used to convert GNSS ellipsoidal heights to the AHD and vice versa, none until now have accounted for the gravimetric quasigeoid to AHD offsets. This offset is a consequence of how the AHD was realised and has commonly resulted in misfits of $\sim 0.5 \mathrm{~m}$ or more. When used with GNSS technology, AUSGeoid09 can replace the need for traditional third-order levelling (Class LC; $12 \sqrt{k}$ ) in many situations. Relative tests of AUSGeoid09 over a continent-wide set of over 20 million baselines showed that it can deliver better than Class LC tolerances in 99\% of cases. The model accepts a user's GDA94 latitude, longitude and ellipsoidal height and returns an AHD height and deviations of the vertical. AUSGeoid09 is now available free-of-charge on the Geoscience Australia website (http://www.ga.gov.au/geodesy/ausgeoid/nvalcomp.jsp).
\end{abstract}

Keywords: AUSGeoid, GNSS heighting, AHD, quasigeoid

\section{Introduction and Background}

Global Navigation Satellite System (GNSS) technology is used for a plethora of positioning and navigation activities due to its speed, convenience and accuracy. A weakness of GNSS is that the heights are not physically meaningful. GNSS provides the user with a height relative to the ellipsoid (ellipsoidal height), a mathematically simplistic representation of the shape of the Earth, not a height relative to a practical reference surface such as the Australian Height Datum (AHD). 
A GNSS ellipsoidal height $(h)$ is converted to an AHD height $(H)$ by subtracting the AUSGeoid $N$ value

$$
H=h-N
$$

In reality, equation (1) is an approximation due to curvature of the plumbline, but this is insignificant (less than a millimetre) when compared to the approximations in the height system used in the AHD (cf. Filmer et al., 2010).

AUSGeoid models have always provided a tool to assist GNSS users to transfer heights from the ellipsoid to AHD and vice versa, however earlier versions of AUSGeoid (e.g. AUSGeoid98; Featherstone et al., 2001) are predominantly gravimetric quasigeoids and provide GNSS users with the height offset between the ellipsoid and gravimetric quasigeoid. The gravimetric-only quasigeoid and AHD differ by $\sim 0.5 \mathrm{~m}$ or more. These offsets are due to the way the AHD was realised (e.g. Featherstone, 2004, 2006; Featherstone and Filmer, 2008) where mean sea level measured at 32 tide gauges around the Australian coastline was assigned a value of 0.000 metres in a constrained adjustment of the Australian National Levellling Network (ANLN) (Roelse et al., 1975).

AUSGeoid09 is the first national geoid to account for the spatially varying differences between the AHD and a gravimetric quasigeoid model (Figure 1). It is provided on a 1' $\mathrm{x} 1$ ' grid over the area $108^{\circ} \mathrm{E}$ to $160^{\circ} \mathrm{E}$ and $8^{\circ} \mathrm{S}$ to $46^{\circ} \mathrm{S}$ and includes deviations of the vertical, at the geoid, computed using the gravimetric-only component, called AGQG2009. The geometric component was computed using a nation-wide co-located set of GNSS-AHD data using least squares collocation (LSC; Moritz, 1980) in cross validation mode (Featherstone and Sproule, 2006). This surface was then added to the gravimetric component of AUSGeoid09 (Featherstone et al., 2011) to model the surface of zero AHD elevation (cf. Featherstone, 1998).

Since the AHD remains Australia's official national vertical datum, it is necessary to provide a 'product' that allows GNSS users to derive AHD heights as accurately as possible. Providing a model of the base of the AHD allows for this. AUSGeoid09 has accounted for the principal limitation associated with previous AUSGeoid models and provides users with an order of magnitude improvement in accessing the AHD. 


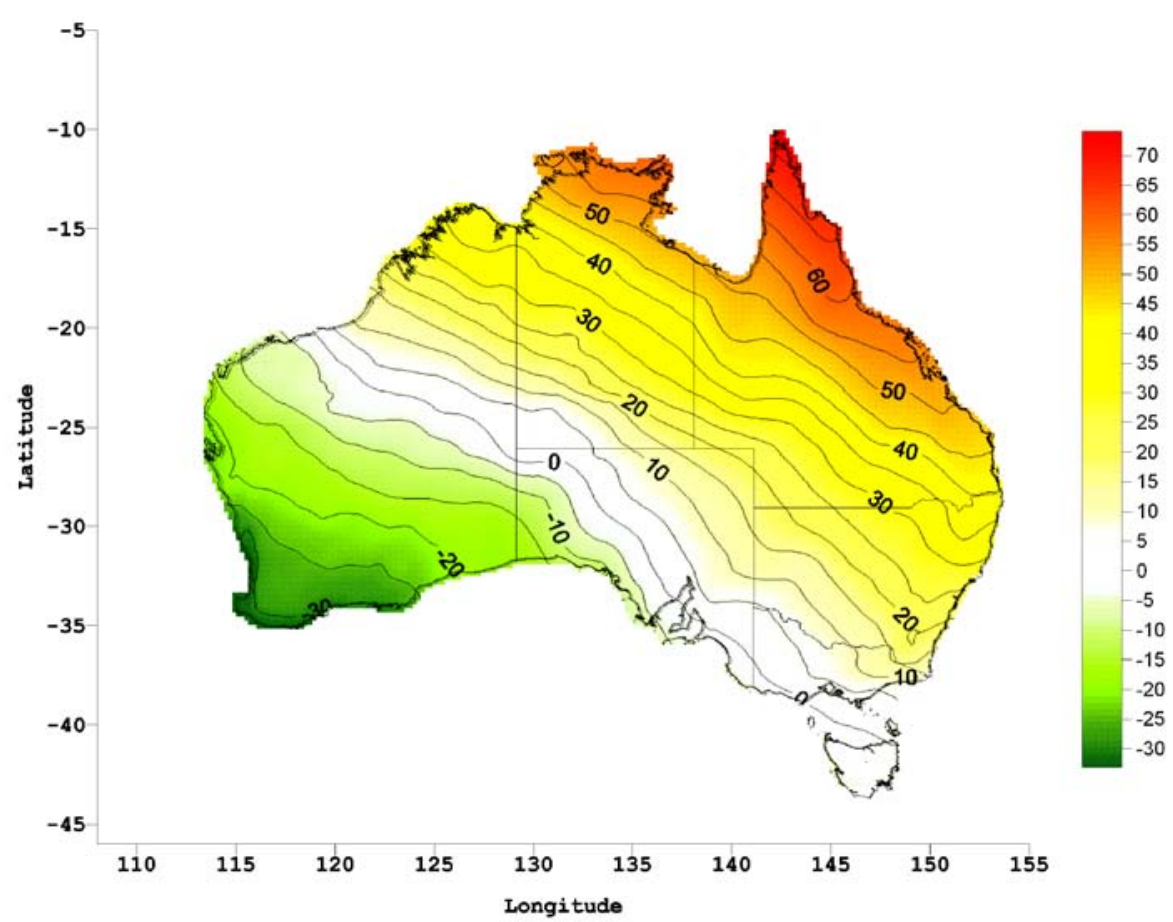

Figure 1. The combined gravimetric - geometric AUSGeoid09 model. (Mercator projection; units in metres)

\section{Data}

AUSGeoid09 comprises two components, gravimetric and geometric, which have been combined to produce an accurate model of the offset between the GRS80 ellipsoid (realised as GDA94) and AHD.

\section{Gravimetric Component}

The datasets used to compute the gravimetric component of AUSGeoid09 are detailed in Featherstone et al. (2011). In short, it used the degree-2190 spherical harmonic expansion of the EGM2008 global gravity model (Pavlis et al., 2008), 1.4 million land gravity anomalies from the Australian national gravity database, the 9" x 9" GEODATA-DEM9S digital elevation model of Australia, and altimeter-derived marine gravity anomalies from the DNSC2008GRA grid (Andersen et al., 2010).

To test the gravimetric component in a way that was less affected by the north-south slope and regional distortions in the AHD (described and cited above), a readjustment of the ANLN constrained to the CARS2006 dynamic ocean topography model (Ridgway et al., 2002) was used. Around 1,000 GNSS heights were used in these tests. The gravimetric-only component (AGQG2009; cf. Featherstone et al., 2011), is reserved for scientific purposes and will not be distributed in an uncontrolled way to avoid confusion and fragmentation.

\section{Geometric Component}

The geometric component of AUSGeoid09 is a model of the spatially variable offset between the AHD and AGQG2009. As will be described in Section 3, AHD-ellipsoid separations $\left(N_{\text {ahd }}\right)$ are compared to the AGQG2009-ellipsoid separations $\left(N_{a g}\right)$ to compute the spatially varying offsets. 
The geometric component was developed using two datasets. The primary dataset of 2,638 co-located GNSS-AHD heights were provided by the State and Territory surveying authorities. The raw GNSS data (minimum of six hours of data in most cases) were processed by Geoscience Australia using the Bernese version 5.0 software (Dach et al., 2007). All data were processed with respect to ITRF2005 (Altamimi et al., 2007) and transformed to GDA94 latitude, longitude and ellipsoidal height using the approach in Dawson and Woods (2010). The co-located AHD heights were predominantly Class LC or better. The $N_{\text {ahd }}$ value at those co-located points was computed using equation (2)

$$
N_{\text {ahd }}=h_{G D A 94}-H_{\text {ahd }}
$$

where $h_{\text {GDA94 }}$, is the GDA94 ellipsoidal height derived from GNSS and, $H_{\text {ahd }}$, is the colocated AHD height.

A secondary dataset of 4,233 levelling junction points (JPs) from the ANLN were also included to provide a higher resolution definition of the offset between the AHD and AGQG2009. Given that the GDA94 ellipsoidal heights are unknown at these JPs, a derived ellipsoidal height was computed, as follows. The $H_{\text {ahd }}$ values of the ANLN were constrained to the gravimetric quasigeoid heights $\left(H_{a g}\right)$ in a readjustment of the ANLN at the 2,638 colocated GNSS-AHD points, thereby warping the ANLN $H_{\text {and }}$ heights onto AGQG2009. This yielded derived gravimetric quasigeoid heights $\left(d H_{a g}\right)$ at each JP. The $N_{a h d}$ values at these points were computed using equation (3).

$$
N_{a h d}=\left(d H_{a g}+N_{a g}\right)-H_{a h d}
$$

The ANLN dataset is the most up-to-date version (GA database version: 29/8/2008) and contains recent changes based on re-levelling information provided by the State and Territory survey authorities. It is also important to note that outliers were not removed given AUSGeoid09 is a "warts and all" model, designed to offer a direct conversion to the AHD. However, the outliers have been communicated to the State and Territory surveying authorities for further investigation.

\section{Methods}

The combined gravimetric-geometric AUSGeoid09 model was developed in two stages. Firstly, the gravimetric component of the 1' $\mathrm{x}$ 1' model was computed using the techniques described in Featherstone et al. (2011). Cross-validated LSC was then used to compute the geometric component that models the spatially varying offset between the gravimetric quasigeoid and the AHD. Finally, the geometric component was added to the gravimetric quasigeoid.

\section{Gravimetric Component}

The theory and methods used to compute the gravimetric component of AUSGeoid09 (AGQG2009) are described in Featherstone et al. (2011) and the references cited therein. In short, AGQG2009 (Figure 2 (top)) uses a hybrid of the remove-compute-restore technique and modified Stokes kernel with a spherical cap. EGM2008 to spherical harmonic degree 
2,190 was used as the reference field in the remove-compute-restore step, whereas a degree40 deterministically modified Stokes kernel was applied over a one-degree spherical cap in the compute step. The combination of the modified kernel and spherical cap filter longwavelength errors from the terrestrial gravity anomalies. The digital elevation model was used to both construct mean land gravity anomalies and apply gravimetric terrain corrections.

To determine the numerical integration parameters for the modified Stokes kernel, AGQG2009 was compared with 911 GNSS observed ellipsoidal heights at benchmarks. This is a subset of the primary dataset of 2,638 co-located points used in the development of the geometric component of AUSGeoid09. AGQG2009 was developed approximately one year prior to AUSGeoid09 and this was the best available data at the time. AGQG2009 was not developed solely for AUSGeoid09; it is an independent product available for scientific purposes.

The standard deviation of fit to the GNSS-AHD heights was $\pm 222 \mathrm{~mm}$, which dropped to $\pm 134 \mathrm{~mm}$ following the readjustment of the GNSS-ANLN heights constrained to the CARS2006 dynamic ocean topography model (Ridgway et al., 2002). The comparisons involved the computation of over 500 prototype quasigeoid models, which was a significant computational challenge. Each grid comprises over seven million nodes, and even when using fast Fourier transform techniques, took many hours (as much as 60 in some cases) even when using a high-performance supercomputer.

\section{Fitting to AHD}

LSC (Moritz, 1980) in the so-called cross validation mode (Featherstone and Sproule, 2006) was used to empirically compute the parameters for the geometric component of AUSGeoid09 (Figure 2 (bottom)). Essentially a form of Kriging (Dermanis, 1984), LSC is a data-driven interpolator; that is, the interpolated value is dependent on the spatial distribution of, and errors in, the discrete data being used. This is distinct to deterministic methods, such as inverse distance weighting or splines, which are based on a predetermined formula or set of criteria governing the properties of the surface being modelled.

The cross validation mode removes one point from the LSC-prediction at a time and that point is then used to assess the accuracy of the combined gravimetric - geometric model computed from the remaining points. This was repeated for all 6,871 points. This approach provides a more independent assessment of the accuracy of the model and the data, contrasted to studies where the same data used to develop the model are used to test it. Importantly, it is not fully independent because the AHD heights used are connected. In this study, we used adapted versions of the GEOGRID routines from the GRAVSOFT suite of computer programs for gravity field modelling and prediction (Tscherning, 1992; Tscherning et al., 1992), as performed in other studies (e.g. Featherstone, 2000).

To compute the offsets $(\varepsilon)$ between AGQG2009 and the AHD (equation 4), the AGQG2009 values were bi-linearly interpolated at each of the GNSS-AHD data points, then subtracted from $N_{\text {ahd }}$.

$$
\varepsilon=N_{a h d}-N_{a g}
$$

The offsets were LSC-predicted onto the same 1' x 1' grid as used by AGQG2009 and algebraically added to produce the combined gravimetric-geometric AUSGeoid09 model. 

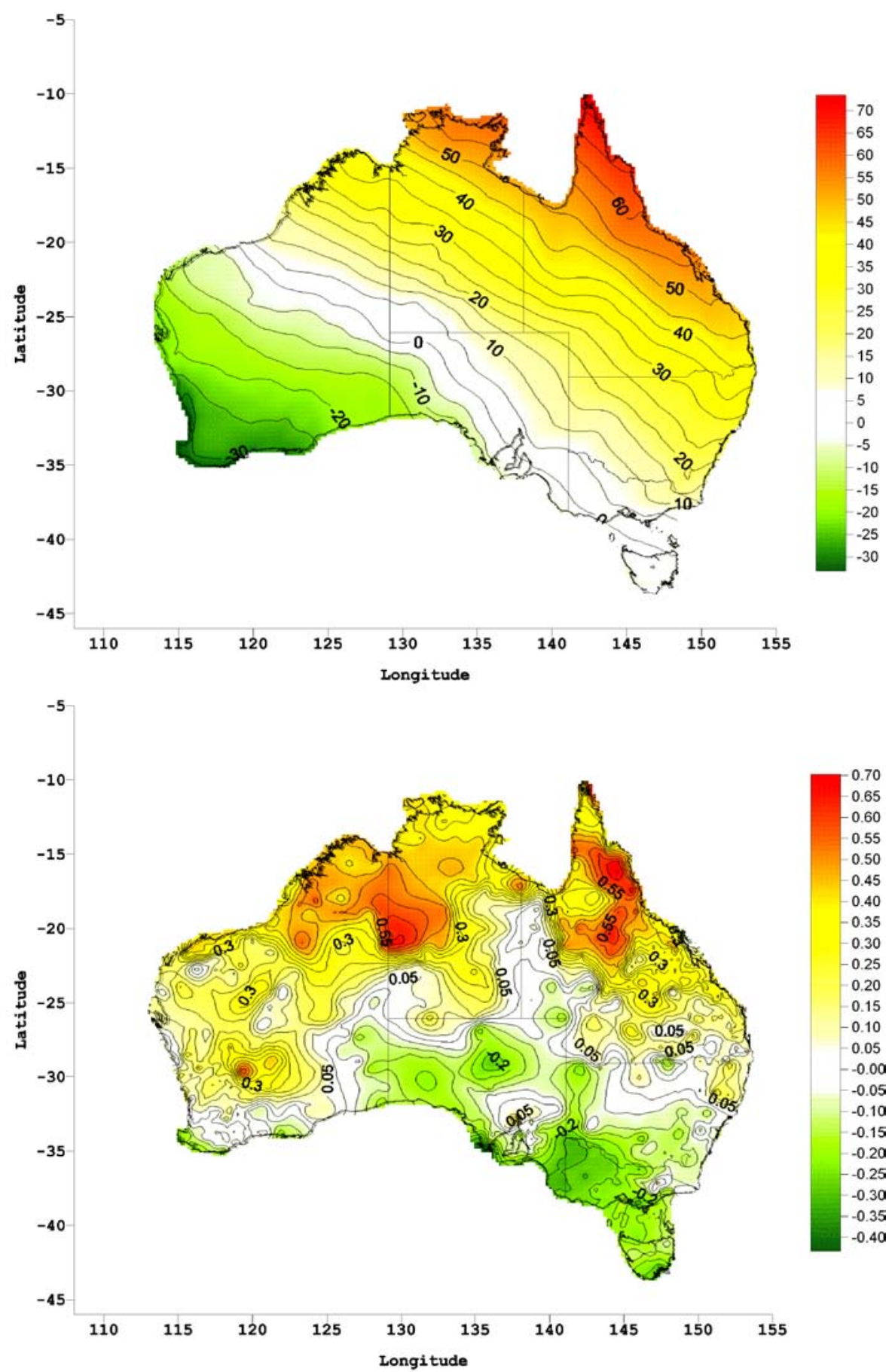

Figure 2. The gravimetric (top) and geometric (bottom) components of AUSGeoid09. (Mercator projection; units in metres)

\section{Testing and Results}

The LSC prediction technique has two principal parameters; the correlation length and RMS noise. The correlation length of the Gaussian covariance function was tested empirically; however, instead of empirically testing the RMS noise parameters (cf. Featherstone and Sproule, 2006), the one sigma uncertainties of the GNSS-AHD points was used. This allows the data to determine the goodness of fit at each location and highlight areas of improvement for the future (see later). 


\section{RMS noise values}

To ensure that AUSGeoid09 fits the AHD within the noise of the GNSS measurements, when weighting the primary dataset we assumed no uncertainty in the AHD heights and adopted the one sigma uncertainties from GNSS analysis. The one sigma uncertainty values of the secondary dataset, $\sigma_{\text {sec }}$, were computed as shown in equation (5)

$$
\sigma_{\mathrm{sec}}=\sqrt{\sigma_{\text {adj }}^{2}+\sigma^{2}{ }_{\mathrm{AGQG} 2009}}
$$

where, $\sigma_{a d j}$, is the uncertainty of the derived AHD height computed in the re-adjustment of the ANLN and, $\sigma_{\mathrm{AGQG} 2009}$, and is the uncertainty in the determination of the AGQG2009 value used in the readjustment. This is due to the imprecision of the coordinates (see below) of the ANLN data, not due to any error in the AGQG2009 model.

The horizontal coordinates of the JPs as given in the ANLN database were scaled from maps, and are only accurate to $0.5^{\prime}(\sim 1.6 \mathrm{~km})$ in latitude and longitude. The change in the AGQG2009 over 0.5' in Australia is on average $\sim 0.05 \mathrm{~m}$. For the purposes of this study, an uncertainty of $0.033 \mathrm{~m}$ (one sigma of $0.05 \mathrm{~m}$ ) was used to represent this inaccuracy. These uncertainties effectively weight the LSC fitting to ensure that the co-located GNSS-AHD data has greater influence on the definition of AUSGeoid09, while the inclusion of the JPs help to represent the higher resolution variability across Australia.

\section{Computing the correlation length}

The correlation length of the Gaussian covariance function was computed empirically. Nine tests were performed in parallel with varying correlation lengths $(10 \mathrm{~km}-500 \mathrm{~km})$ on the Geoscience Australia “tornado" cluster; a 21-node cluster each with two dual-core CPUs. These tests took approximately two weeks to complete.

The optimal correlation length of those tested was found to be $75 \mathrm{~km}$. As shown in Figure 3, this is where the RMS of differences between the GNSS-AHD data points and LSCcombined models was at a minimum (less than $0.030 \mathrm{~m}$ ). This indicates that GNSS users will be able to compute an AHD height from GNSS and AUSGeoid09 with an accuracy of \pm 0.030 $\mathrm{m}$ (one sigma). This is an order of magnitude improvement when compared with AUSGeoid98, which had a RMS fit of $\pm 0.364 \mathrm{~m}$ (Featherstone et al., 2001), albeit to an older vintage of GNSS-AHD data. 


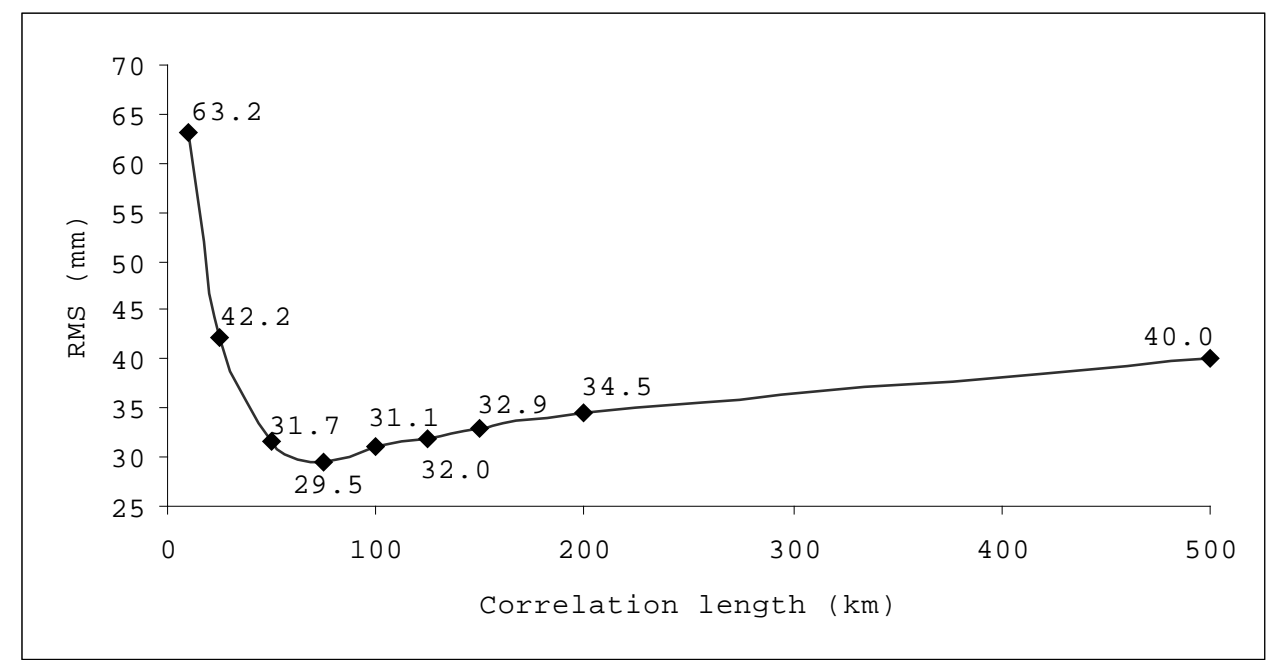

Figure 3. RMS of differences between the GNSS-AHD data points and LSC-combined models for variations in correlation length of the covariance function.

\section{Relative Testing}

As described in Featherstone (2001), relative testing is appropriate since GNSS is rarely used in an absolute sense for surveying. These GNSS users are generally more concerned with the height differences between two or more points. It is therefore more informative to compare the AHD height differences, recovered using GNSS and AUSGeoid09.

Relative testing was performed using 6,672 of the 6,871 points from the combined dataset. Vincenty's (1975) formula in the relative tester software (Featherstone, 2001) considered 199 of the points to be too close to another point in the dataset, and therefore they were omitted from this test. The remaining points were used to form 22,254,456 baselines $(m=n(n-1) / 2$, where $n$ is the number of points). Table 1 shows the descriptive statistics for the relative test of the AUSGeoid09 and AUSGeoid98 models.

Table 1: Descriptive statistics of the relative differences between the AUSGeoid09 and AUSGeoid98 models and 6672 GNSS-AHD data. Units in metres.

\begin{tabular}{|c|c|c|c|c|c|}
\hline Model & Max & Min & Mean & RMS & Baselines $>$ Class LC \\
\hline AUSGeoid09 & 0.444 & -0.408 & 0.001 & 0.030 & $(21,702 / 22,254,456)=0.1 \%$ \\
\hline AUSGeoid98 & 2.725 & -1.354 & 0.226 & 0.380 & $(5,066,836 / 22,254,456)=22.8 \%$ \\
\hline
\end{tabular}

A somewhat more meaningful test is to determine the descriptive statistics for baselines shorter than $100 \mathrm{~km}$ (Table 2); a distance beyond which very few GNSS surveys would be undertaken. This reduces the number of baselines to 622,982.

Table 2: Descriptive statistics of the relative differences between the AUSGeoid09 and AUSGeoid98 models and 6672 GNSS-AHD data (baselines less than $100 \mathrm{~km}$ ). Units in metres.

\begin{tabular}{|c|c|c|c|c|c|}
\hline Model & Max & Min & Mean & RMS & Baselines $>$ Class LC \\
\hline AUSGeoid09 & 0.346 & -0.330 & 0.000 & 0.029 & $(18,354 / 622,982)=2.9 \%$ \\
\hline AUSGeoid98 & 1.604 & -1.296 & 0.027 & 0.109 & $(254,421 / 622,982)=40.8 \%$ \\
\hline
\end{tabular}

\section{Discussion}


The RMS of the relative differences between AUSGeoid09 and the GNSS-AHD data points is similar to the results of the cross validation testing with a RMS value of $\sim 0.03 \mathrm{~m}$ across all baselines, and baselines shorter than $100 \mathrm{~km}$. This suggests that AUSGeoid09 is capable of replacing third-order levelling in many circumstances, with less than $3 \%$ of baselines exceeding the ICSM (2004) Class LC levelling specifications when restricted to baselines shorter than $100 \mathrm{~km}$. This is a major improvement when compared to AUSGeoid98 which shows $\sim 41 \%$ of baselines exceeding Class LC tolerances for baselines shorter than $100 \mathrm{~km}$.

Although this is a significant improvement, some misfits (differences between AUSGeoid09 derived AHD heights and ANLN AHD heights) still remain. Figure 4 displays the magnitude of the misfits for the 6871 GNSS-AHD data points and highlights those areas where improvements can be made either by the inclusion of more GNSS data, the removal of gross errors in the AHD, or both.

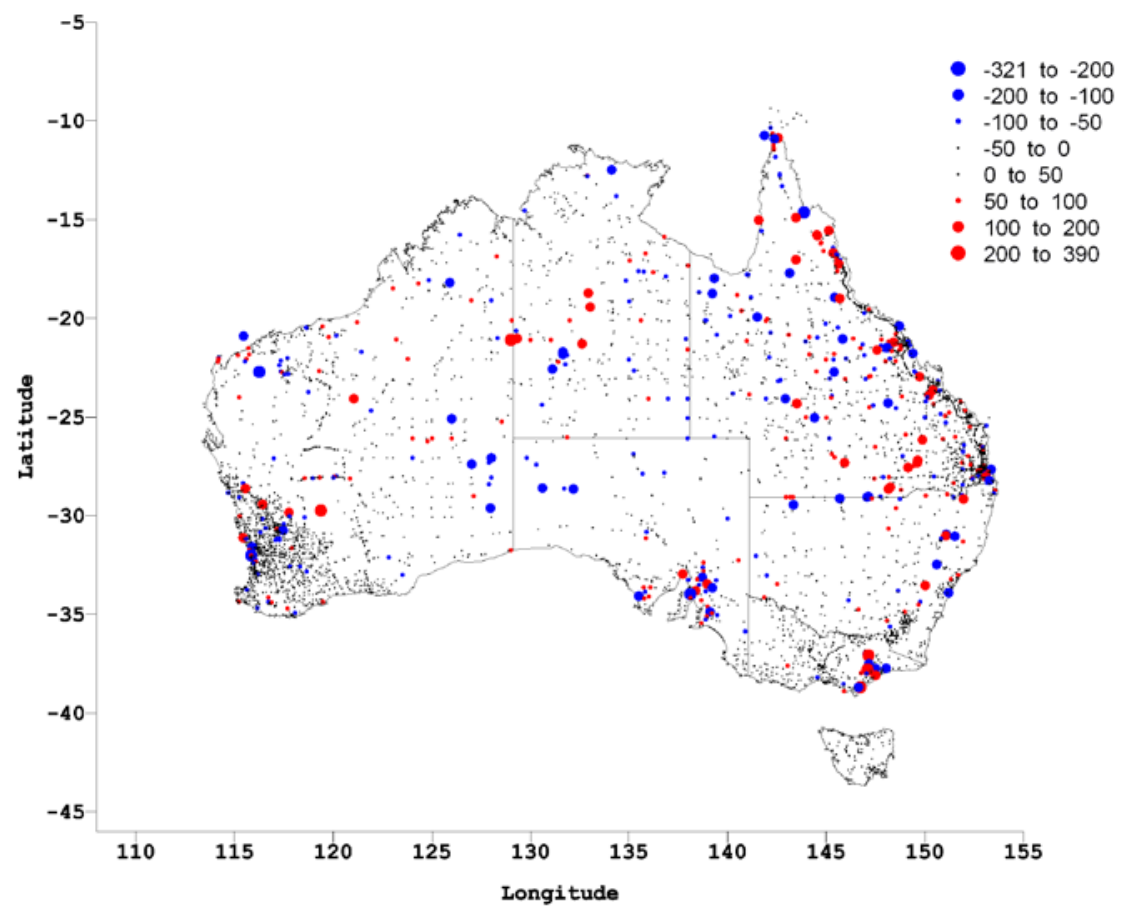

Figure 4. Misfit plot of AUSGeoid09. Red represents ANLN AHD heights that are below the AUSGeoid09 surface and blue represents ANLN AHD heights that are above the AUSGeoid09 surface. (Mercator projection; units in millimetres)

There are still areas of improvement in each State and Territory with a number of points which misfit by $0.1 \mathrm{~m}$ to $0.3 \mathrm{~m}$ and a few extreme misfits $(>0.3 \mathrm{~m})$. These misfits are likely caused by local distortions and blunders in the AHD or difficulties in modelling the gravimetric quasigeoid in coastal and mountainous areas. Geoscience Australia along with the State and Territory survey authorities will endeavour to resolve these misfits and provide updated versions of AUSGeoid09 over the coming years.

Previous assessment studies of AUSGeoid models have rightly claimed that they could not be used in an absolute sense, e.g., in conjunction with AUSPOS due to the size of residuals (e.g., a maximum of $0.780 \mathrm{~m}$ with AUSGeoid98 (Featherstone and Sproule, 2006)). The inclusion of the geometric component of AUSGeoid09 has largely resolved this limitation with the cross validation testing showing it is capable of converting GNSS heights to AHD heights with an uncertainty of $0.030 \mathrm{~m}$ (one sigma) and $0.085 \mathrm{~m}$ (three sigma). 


\section{Concluding Remark}

Results of this study show the combined gravimetric-geometric AUSGeoid09 model is an order of magnitude more accurate than AUSGeoid98 for recovering AHD heights from GNSS, with an uncertainty of $0.030 \mathrm{~m}$ (one sigma). This improvement is largely the result of the addition of a geometric component that models the spatially varying offsets between the AGQG2009 gravimetric quasigeoid model and the AHD. Although previous AUSGeoid models have been acceptably accurate when used in a relative sense, now with AUSGeoid09, GNSS users can convert ellipsoidal heights to AHD heights in an absolute sense to within $0.085 \mathrm{~m}, 99.7 \%$ of the time. This new model allows GNSS users to compute accurate AHD heights in near-real-time, or via post processing. It is hoped this will lead to significant efficiency gains in industries such as mining, agriculture and construction that will no longer need to develop their own localised geometric models.

Acknowledgements: Nicholas Brown, Guorong Hu and Gary Johnston publish with the permission of the Chief Executive Officer of Geoscience Australia. The authors would like to acknowledge Intergovernmental Committee on Surveying and Mapping members for supplying data for the model. Will Featherstone is supported under the ARC's Discovery Projects funding scheme (project number DP0663020). The views expressed herein are those of the authors and are not necessarily those of the ARC. Part of this work was also supported by iVEC (http://www.ivec.org/) through the use of advanced computing resources provided by the SGI Altix facility located at Technology Park, Perth, Australia. Special thanks to Roger Fraser for developing and allowing free access to the interpolation software used on Geoscience Australia's website application. Also, special thanks go to the Danish National Space Centre, CSIRO Marine Laboratories and the US National Geospatial Intelligence Agency for making their data freely available. This study made use of some GPS data collected through the AuScope initiative. AuScope Ltd is funded under the National Collaborative Research Infrastructure Strategy (NCRIS), an Australian Commonwealth Government Programme.

\section{References}

Altamimi Z., Collilieux X., Legrand J., Garayt B., Boucher C. (2007) ITRF2005: A new release of the International Terrestrial Reference Frame based on time series of station positions and Earth Orientation Parameters, Journal of Geophysical Research vol. 112, B09401, doi:10.1029/2007JB004949.

Andersen O. B., Knudsen P., Berry P. A. M. (2010) The DNSC08GRA global marine gravity field from double retracked satellite altimetry, Journal of Geodesy, vol. 84, no. 3, pp. 191199, doi: 10.1007/s00190-009-0355-9.

Dach, R., Hugentobler, U., Fridez, P. and Meindl, M. (eds.) (2007) Bernese GPS software version 5.0, Astronomical Institute, University of Bern, pp. 612.

Dawson, J. and Woods, A. (2010) ITRF to GDA94 coordinate transformations, Journal of Applied Geodesy, vol. 4, no. 4, pp. 189-199, doi: 10.1515/JAG.2010.019.

Dermanis, A. (1984) Kriging and collocation - a comparison, manuscripta geodetica, vol. 9, no. 3, pp. 159-167. 
Featherstone, W. E. (1998) Do we need a gravimetric geoid or a model of the base of the Australian Height Datum to transform GPS heights? The Australian Surveyor, vol. 43, no. 4, pp. 273-280.

Featherstone, W. E. (2000) Refinement of a gravimetric geoid using GPS and levelling data, Journal of Surveying Engineering, vol. 126, no. 2, pp. 27-56, doi: 10.1061/(ASCE)07339453(2000)126:2(27).

Featherstone, W.E. (2001) Absolute and relative testing of gravimetric geoid models using Global Positioning System and orthometric height data, Computers \& Geosciences, vol 27, no.7, pp.807-814, doi: 10.1016/S0098-3004(00)00169-2.

Featherstone, W. E. (2004) Evidence of a north-south trend between AUSGeoid98 and the AHD in southwest Australia, Survey Review, vol. 37, no. 291, pp. 334-343.

Featherstone, W. E. (2006) Yet more evidence for a north-south slope in the AHD, Journal of Spatial Science, vol. 51, no. 2, pp. 1-6. [Corrigendum in Journal of Spatial Science, vol. 52, no. 1, pp. 65-68]

Featherstone, W. E. and Filmer, M. S. (2008) A new GPS-based evaluation of distortions in the Australian Height Datum in Western Australia, Journal of the Royal Society of Western Australia, vol. 91, no. 2, pp. 199-206.

Featherstone, W. E. and Sproule, D. M. (2006) Fitting AUSGeoid98 to the Australian Height Datum using GPS data and least squares collocation: application of a cross-validation technique, Survey Review, vol. 38, no. 301, pp. 573-582.

Featherstone, W. E., Kirby, J. F., Hirt, C., Filmer, M.S., Claessens, S. J., Brown, N. J., Hu, G. and Johnston, G.M. (2011) The AUSGeoid09 model of the Australian Height Datum, Journal of Geodesy 85(3), vol. 85, no. 3, doi: 10.1007/s00190-010-0422-2.

Featherstone, W. E., Kirby, J. F., Kearsley, A. H. W., Gilliland, J. R., Johnston, G. M., Steed, J., Forsberg, R. and Sideris, M. G. (2001) The AUSGeoid98 geoid model of Australia: data treatment, computations and comparisons with GPS-levelling data, Journal of Geodesy, vol. 75, no. 5-6, pp. 313-330, doi: 10.1007/s001900100177.

Filmer, M. S., Featherstone, W. E. and Kuhn, M. (2010) The effect of EGM2008 - based normal, normal-orthometric and Helmert orthometric height systems on the Australian levelling network. Journal of Geodesy, vol. 84, no. 8, pp. 501-513, doi: 10.1007/s00190-0100388-0.

ICSM (2004) Geocentric Datum of Australia Technical Manual, Version 2.3, Intergovernmental Committee on Surveying and Mapping, http://www.icsm.gov.au/icsm/gda/gdatm/index.html

Moritz, H. (1980) Advanced Physical Geodesy, Wichmann, Karlsruhe. 
Pavlis, N. K., Holmes, S. A., Kenyon, S. C. and Factor, J. K. (2008) An Earth Gravitational Model to degree 2160: EGM2008. Paper presented at the general assembly of the European Geosciences Union, Vienna, April.

Ridgway, K.R., Dunn, J.R. and Wilkin, J.L. (2002) Ocean interpolation by four-dimensional weighted least squares-application to the waters around Australasia, Journal of Atmospheric and Oceanic Technology, vol. 19, pp. 1357-1375.

Roelse, A., Granger, H. W. and Graham, J. W. (1975) The Adjustment of the Australian Levelling Survey 1970 - 1971, Technical Report 12 - Second Edition, Division of National Mapping, Canberra, pp. 81.

Tscherning, C.C. (1992) GEOCOL - A FORTRAN program for gravity field approximation by collocation (10th edition). Technical Note, Geophysical Department, University of Copenhagen, Copenhagen.

Tscherning, C.C., Forsberg, R. and Knudsen, P. (1992) The GRAVSOFT Package for Geoid Determination, in Holota, P. and Vermeer, M. (eds), Proceedings of the First Continental Workshop on the Geoid in Europe, Prague, pp. 327-334.

Vincenty, T. (1975) Direct and inverse solutions of geodesics on the ellipsoid with application of nested equations. Survey Review, vol. XXII, no. 176, pp. 88-93. 